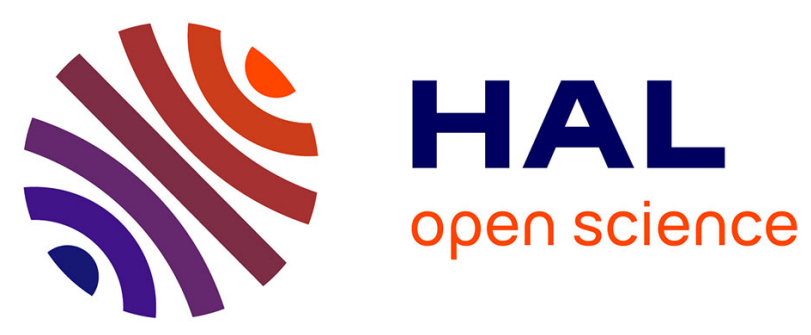

\title{
Correlation of c-MET Expression with PD-L1 Expression in Metastatic Clear Cell Renal Cell Carcinoma Treated by Sunitinib First-Line Therapy \\ Solène-Florence Kammerer-Jacquet, Sarah Médane, Karim Bensalah, Jean-Christophe Bernhard, Mokrane Yacoub, Frantz Dupuis, Alain Ravaud, Grégory Verhoest, Romain Mathieu, Benoit Peyronnet, et al.
}

\section{To cite this version:}

Solène-Florence Kammerer-Jacquet, Sarah Médane, Karim Bensalah, Jean-Christophe Bernhard, Mokrane Yacoub, et al.. Correlation of c-MET Expression with PD-L1 Expression in Metastatic Clear Cell Renal Cell Carcinoma Treated by Sunitinib First-Line Therapy. Targeted Oncology, 2017, 12 (4), pp.487-494. 10.1007/s11523-017-0498-1 . hal-01578072

HAL Id: hal-01578072

https://hal-univ-rennes1.archives-ouvertes.fr/hal-01578072

Submitted on 6 Oct 2017

HAL is a multi-disciplinary open access archive for the deposit and dissemination of scientific research documents, whether they are published or not. The documents may come from teaching and research institutions in France or abroad, or from public or private research centers.
L'archive ouverte pluridisciplinaire HAL, est destinée au dépôt et à la diffusion de documents scientifiques de niveau recherche, publiés ou non, émanant des établissements d'enseignement et de recherche français ou étrangers, des laboratoires publics ou privés. 
4 Short title: c-MET in metastatic renal carcinoma

5 Solène-Florence Kammerer-Jacquet ${ }^{1}$, Sarah Medane ${ }^{1}$, Karim Bensalah ${ }^{2}$, Jean-Christophe Bernhard ${ }^{3}$, Mokrane

6 Yacoub $^{4}$, Frantz Dupuis ${ }^{4}$, Alain Ravaud ${ }^{5}$, Grégory Verhoest ${ }^{2}$, Romain Mathieu ${ }^{2}$, Benoit Peyronnet ${ }^{2}$, Angélique

7 Brunot $^{6}$, Brigitte Laguerre ${ }^{6}$, Alexandra Lespagnol ${ }^{7}$, Jean Mosser ${ }^{7}$, Frédéric Dugay ${ }^{8}$, Marc-Antoine Belaud-

8 Rotureau $^{8}$ and Nathalie Rioux-Leclercq ${ }^{1}$

${ }^{1}$ Université de Rennes 1, UMR 6290-IGDR, Univ Bretagne Loire, CHU de Rennes, Service d'Anatomie et 11 Cytologie Pathologiques, F-35042 Rennes, France

$12{ }^{2}$ Université de Rennes 1, CHU de Rennes, Service d'Urologie, F-35042 Rennes, France

$13{ }^{3}$ Service d'Urologie, CHU Pellegrin, Bordeaux, France

$14{ }^{4}$ Service d'Anatomie et Cytologie Pathologiques, CHU Pellegrin, Bordeaux, France

155 Service d'Oncologie Médicale, CHU Saint-André, Bordeaux, France

$16{ }^{6}$ Centre Eugène Marquis, Service d'Oncologie Médicale, Université de Rennes 1, Rennes, France $17{ }^{7}$ Université de Rennes 1, UMR 6290-IGDR, Univ Bretagne Loire, CHU de Rennes, Service de Génétique 18 Somatique des Cancers, F-35042 Rennes, France

$19{ }^{8}$ Université de Rennes 1, UMR 6290-IGDR, Univ Bretagne Loire, CHU de Rennes, Service de Cytogénétique et 20 Biologie cellulaire, F-35042 Rennes, France 
ABSTRACT

Background: Clear cell renal cell carcinoma (ccRCC) are highly metastatic. Cabozantinib, an antiangiogenic tyrosine kinases inhibitor, targeting c-MET, proved interesting results in metastatic ccRCC treatment.

Objective: To better understand c-MET role, we assessed its status in a population of patients with metastatic ccRCC.

Patients and methods: For this purpose, c-MET expression was studied by immunohistochemistry (IHC), $c$ MET copy number alteration, by fluorescence in situ hybridization (FISH) and $c-M E T$ mutation, by next generation sequencing (NGS) in a retrospective cohort of 90 primary ccRCC of patients with metastases treated by first-line sunitinib. The expression of c-MET was correlated with pathological, immunohistochemical (VEGFA, CAIX, PD-L1), clinical and molecular criteria (VHL status) by univariate and multivariate analyses and to clinical outcome using Kaplan Meier curves compared by log-rank test.

Results: $31.1 \%$ of ccRCC had c-MET low expression (absent to weak intensity by IHC) versus $68.9 \%$ with high expression (moderate to strong intensity). The high expression of c-MET was associated with a gain in FISH analyses $(p=0.0284)$ without amplification. No mutation was detected in NGS. Moreover, high c-MET expression was associated with lymph node metastases $(\mathrm{p}=0.004)$, sarcomatoid component $(\mathrm{p}=0.029)$, VEGFA overexpression $(\mathrm{p}=0.037)$ and PD-L1 $(\mathrm{p}=0.001)$, the only factor that remained independently associated $(\mathrm{p}<0.001)$ after logistic regression. No difference was observed in clinical outcome.

Conclusion: This study is the first to analyse c-MET status in metastatic ccRCC. The high expression of c-MET in the majority of ccRCC and its independent association with PD-L1 expression, may suggest a potential benefit from c-MET inhibitors and targeted immunotherapy in combination.

- This study is the first to assess c-MET status, in metastatic renal carcinoma treated with anti-angiogenic therapy.

- The high expression of c-MET was observed in the majority of patients and independently associated with the overexpression of PD-L1.

- These findings may suggest a potential benefit from the combination of c-MET inhibitors and targeted immunotherapy. 


\section{INTRODUCTION}

Renal cell carcinoma (RCC) is the most common form of kidney cancer with more than 270000 cases diagnosed worldwide and an estimated of 110000 deaths from this tumour annually [1]. The most frequent histological subtype is clear cell RCC (ccRCC), representing 70\% of all renal cancers [2]. This subtype is a highly aggressive tumour, as 40 to $50 \%$ of patients with ccRCC develop metastases: 20 to $30 \%$ of patients have metastatic disease at diagnosis, while $30 \%$ of patients who have local RCC will develop metastases during follow-up [3].

Inactivation of the von Hippel-Lindau (VHL) tumour-suppressor protein has been described in more than $80 \%$ of ccRCC, resulting in the stabilization of Hypoxia Inducible Factor (HIF) and the up-regulation of vascular endothelial growth factor (VEGF) production [4]. A better understanding of the molecular pathways involved in ccRCC contributed to the development of anti-angiogenic drugs, such as sunitinib or pazopanib, but longstanding responses are rare $[5,6]$.

New strategies to treat metastatic ccRCC are in development. The first strategy is based on targeted immunotherapy using checkpoint inhibitors (such as anti-PD-1/PD-L1). A recent clinical trial demonstrated nivolumab (an anti-PD-1) superiority over everolimus, an inhibitor of mammalian target of rapamycin (mTOR), in second-line treatment [7]. Another approach uses a novel antiangiogenic tyrosine kinase inhibitor (TKI), cabozantinib, which has the particularity to target c-MET and also showed interesting results in second-line treatment compared to everolimus [8].

The tyrosine kinase receptor c-MET is a proto-oncogene involved in tumour angiogenesis, proliferation and metastasis. The dysregulation of c-MET and its ligand, hepatocyte growth factor (HGF), has been implicated in a range of malignancies including renal cancers [9-11]. c-MET can be activated through several mechanisms such as the mutation of the tyrosine kinase receptor domain or gene amplification and protein overexpression [6]. Although cabozantinib is a promising therapy, c-MET status has never been assessed in metastatic ccRCC.

The aim of the present study was to verify whether c-MET is activated in metastatic ccRCC in order to optimize the use of c-MET inhibitors in such tumours. For this purpose, we assessed c-MET status in a retrospective cohort of 90 patients with metastatic ccRCC treated by first-line sunitinib therapy.

\section{MATERIALS AND METHODS}

\subsection{Patients and pathological analysis}

99 Primary ccRCC-specimens were collected from 90 patients undergoing nephrectomy in 2 French University

100 Hospitals (Rennes, $\mathrm{n}=46$ and Bordeaux, $\mathrm{n}=44$ from UroCCR database) from 1997 to 2013 with metastases that appeared between 2005 and 2013. When the metastases appeared, these patients were treated with antiangiogenic sunitinib (Sutent $\left.{ }^{\circledR}\right)$ therapy, as a first-line treatment. For each case, clinical, biological and radiological features were obtained from referring physicians and medical records. The response to treatment was assessed using response evaluation criteria in solid tumours (RECIST), the first evaluation was assessed after 2 cycles of sunitinib ( 3 months). The study protocol was approved by the local advisory board (CNIL declaration receipt 1812601v0) and informed consent was obtained from each patient. The macroscopic and

107 histological parameters analysed were tumour size, nucleolar grade according to the International Society of 
Urological Pathology (ISUP) grading system, sarcomatoid component, tumour necrosis and microvessel invasion. Tumour stage was defined according to the latest International Union Against Cancer 2009 classification. For each tumour, formalin-fixed paraffin-embedded (FFPE) and frozen samples were available.

\subsection{Immunohistochemistry}

113 For each ccRCC case, a representative slide of the tumour with the highest nucleolar grade and the 114 corresponding paraffin block was selected. Four $\mu$ m-thick whole tissue sections were cut and mounted on glass 115 slides (Superfrost + , Menzel Glazer). The preparations were dried for 1 hour at $58^{\circ} \mathrm{C}$, and then overnight at $37^{\circ} \mathrm{C}$.

116 The sections were deparaffinized with toluene and rehydrated with ethanol. The preparations were pretreated and 117 immunostained using Ventana Benchmark XT. c-MET (Anti-Total c-MET, SP44, Rabbit Monoclonal Primary 118 Antibody, ready-diluted, Ventana, Roche, Switzerland), VEGFA (Anti-VEGF antibody, sc-152, dilution 1/100 ; 119 Santa Cruz Biotechnology, Santa Cruz, CA, USA), CAIX (Anti-CAIX antibody, ab15086, dilution 1/1500, 120 Abcam, Cambridge, UK), PD-L1 (Anti-PD-L1 antibody, clone 130021, dilution 1/200, RD System, 121 Minneapolis, USA) and PD1 (anti-PD-1 antibody, clone NAT105, dilution 1:50; Abcam, Cambridge, UK) 122 expressions were assessed by immunohistochemistry as previously described [12-15]. The reactivity of antibody 123 was revealed with HRP-labeled polymer conjugated secondary antibody using diaminobenzidine (DAB) as 124 chromogen (Sigma-Aldrich, France). Appropriate positive and negative controls were used. Two pathologists 125 (SM, SFKJ) and one uropathology expert (NRL) independently scored immunomarkers expression. The cut-off 126 for positive cases was 30\% of tumour cells for VEGF and 85\% for CAIX as previously described [16, 17]. For 127 PDL1, absent (0), weak (1), moderate (2) and strong expression (3) were reported and cases were then 128 subdivided into negative (score $0-1$ ) or positive (score 2-3) subgroups [15]. For PD1, immunostaining density 129 was evaluated in tumour-infiltrating lymphocytes and was semi-quantified as absent (0), rare (1), moderate (2) or 130 dense (3); cases were then subdivided into negative (score $0-1$ ) or positive (score $2-3$ ) subgroups [18, 14]. For c131 MET IHC, membranous and cytoplasmic staining were considered. The intensity of the staining was scored as 132 absent (0), weak (1), moderate (2) or strong (3) as previously assessed [15]. For statistical analysis, c-MET 133 expression was considered high when moderate or strong staining was observed and low when the staining was 134 absent or weak.

\subsection{Fluorescent in situ hybridization}

137 FISH analyses were performed on the Rennes cohort ( $\mathrm{n}=46$ ). FISH analyses were performed on $4 \mu \mathrm{m}$ sections of 138 FFPE tumour tissue with the ZytoLight ${ }^{\circledR}$ SPEC c-MET (7q31, Spectrum Green ${ }^{\circledR}$ ) / CEN 7 (Spectrum Orange ${ }^{\circledR}$ ) 139 Dual Color Probe (Zytovision, Bremerhaven, Germany). One cytogeneticist (MABR) independently analysed 140 FISH. The slides were deparaffinized with xylene using a VP2000processor (Abbott, Wiesbaden, Germany). The 141 tissue was digested with pepsin (Dako, Les Ulis, France) for $6 \mathrm{~min}$. The target DNA and probe were co142 denatured for $10 \mathrm{~min}$ at $75^{\circ} \mathrm{C}$ using a programmable system (Thermobrite, Abbott Laboratories, North Chicago, 143 Illinois, USA) and probe hybridization was performed overnight in a humidified atmosphere at $37^{\circ} \mathrm{C}$. The slides 144 were analysed using a fluorescence microscope (BX61, Olympus, Rungis, France) and Isisimaging software 145 (Metasystems, Altlussheim, Germany) [19]. The entire hybridized surface was screened using a double band146 pass filter with an X63 objective and 50 non-overlapping tumour nuclei were examined. For the c-MET analysis, 
gain (copy number alteration) was defined by strictly more than 2 c-MET signals and amplification was defined according to UCCC (University of Colorado Cancer Center) scoring system [20].

\subsection{Next generation sequencing}

Small samples were collected from surgical specimens, frozen in liquid nitrogen and stored at $-80^{\circ} \mathrm{C}$ until DNA extraction. Genomic DNA was extracted using QIAamp DNA minikit (Qiagen, Courtaboeuf, France). DNA quantity and quality were estimated by optical density (OD 260/280) measurement and 0,8\% agarose gel electrophoresis using standard protocols. Sequencing amplicon libraries were prepared using the TruSeq Amplicon Cancer Panel (Illumina Inc., San Diego, California), according to the manufacturer's instructions. DNA target preparation and enrichment were performed using the Access Array ${ }^{\circledR}$ polymerase chain reaction (PCR) system (Fluidigm, San Francisco, USA). A 6-nucleotide "barcode" tag, specific to each sample and Illumina-specific sequencing adaptors were attached using secondary PCR. Purified products were subsequently pooled and sequenced on the Illumina MiSeq NGS instrument (Illumina Inc., San Diego, California). For the $c$ $M E T$ gene, exons 2, 14, and 16 to 20 were fully sequenced to identify mutations in the tyrosine kinase domain. For the $V H L$ gene, the entire coding sequence and exon-intron junctions of exons 1, 2 and 3 were analysed.

162

\subsection{Multiplex Ligation-dependant Probe Amplification}

164 Methylation-Specific-MLPA (MS-MLPA) was used to detect CpG islands methylation in the VHL gene 165 promoter [21]. The SALSA MS-MLPA kit ME001B Tumour suppressor-1 was used to detect the aberrant 166 methylation of CpG-islands located in the promoter region of the VHL gene. The DNA (50-200 ng) was denatured and the probes were allowed to hybridize $\left(16 \mathrm{~h}\right.$ at $\left.60^{\circ} \mathrm{C}\right)$. The VHL probes used for the methylation quantification analysis contained one methylation-sensitive restriction site (HhaI) in the target recognition sequence. Following hybridization, the samples were divided in half and one half of the samples was ligated, whereas ligation was combined with HhaI digestion enzyme for the other part of the sample. This digestion resulted in the ligation of only the methylated sequences. PCR was performed on all the samples and the products were then analysed by electrophoresis. Reference unmethylated DNA samples, isolated from blood

173 from healthy volunteers, were included in each set of MLPA experiments. Unmethylated DNA will not generate a signal, and a normal probe signal will be detected if the site is methylated.

\subsection{Statistical analysis}

177 Chi2 (or Fisher exact) and Mann-Whitney tests were performed to compare qualitative and quantitative 178 parameters respectively between groups. For logistic regression, we used a backward stepwise selection with $179 \mathrm{p}<0.05$ inclusion criteria. For clinical outcome, we calculated PFS from the date of sunitinib introduction to the 180 date of progression and OS from the date of sunitinib introduction to the date of specific death or last contact. All

181 p-values were 2-sided, and p-values less than 0.05 were considered statistically significant. All statistical 182 analyses were performed using Stata 14.1 software (College Station, TX).

183

\section{3. RESULTS}

$185 \quad 3.1$ Patients and histological parameters

186 The mean age at diagnosis was 61 years (37-85). The mean tumour size was $8.7 \mathrm{~cm}$ with tumours ranging from 2 
$\mathrm{cm}$ to $20 \mathrm{~cm}$. A total of 69 patients $(76.6 \%)$ had an ECOG performance status of 0 . In 50 cases $(55.5 \%)$, metastases were present at diagnosis. Non-metastatic tumours at diagnosis developed metastases on average after 10.5 months (0-144 months). The mean follow-up was 43.9 months (1-171 months) from nephrectomy. Eightyfive patients (94.4\%) experienced progression and 71 patients (78.9\%) died from their cancer. The mean followup period was 25.9 months (range 1-76 months) from sunitinib introduction. The population characteristics and pathological parameters are summarized in Table 1.

195 VHL status was assessed in the entire cohort $(\mathrm{n}=90)$. All patients were negative for germ-line mutations. A VHL 196 gene mutation was observed in 64 cases (71.1\%). Mutations occurred in exons 1, 2 and 3 in 28 (43.8\%), 21 $197(32.8 \%)$ and 15 cases (23.4\%) respectively. Stop, frameshift, missense, and splice site mutations were detected in $1988(12.5 \%), 34(53.1 \%), 18(28.1 \%)$ and $4(6.3 \%)$ cases respectively. VHL promoter methylation occurred in 10 cases (11.1\%). At least one or more $V H L$ abnormalities (VHL inactivation) were observed in 74 cases $(82.2 \%)$.

\section{$\underline{3.3 \mathrm{c}-\mathrm{MET} \text { status }}$}

For c-MET immunostaining, $11.1 \%(n=10)$ of ccRCC cases were negative, while $20.0 \%(n=18)$ of ccRCC cases had weak staining. Moderate staining was observed in $26.7 \%(n=24)$ of cases and strong staining was observed in $42.2 \%(n=38)$ of cases. Overall, $31.1 \%(n=28)$ of tumours were considered low and $68.9 \%(n=62)$ of cases were considered high for c-MET expression. In the NGS analysis for the 90 patients, $c-M E T$ status was assessed in 90 tumours. DNA quality was acceptable for 75 samples and no mutation was identified. $c$-MET FISH status was assessed in 39 out of 46 interpretable cases. Gains were observed without amplification of $c$-MET. Two copies were observed. The mean percentage of cells with gains was significantly associated with c-MET high expression $(\mathrm{p}=0.0284)$.

3.4 Correlation of c-MET expression with pathological, immunohistochemical and molecular characteristics and clinical outcomes

213 Tumours with low or high c-MET expression and patients characteristics were summarized and compared in

214 Table 2. Overall, high c-MET expression was not associated with progression at first radiologic evaluation. High $215 \mathrm{c}$-MET expression was also associated with high ISUP nucleolar grade ( $\mathrm{p}=0.037)$, lymph node status ( $\mathrm{p}=0.004)$ 216 and sarcomatoid component $(\mathrm{p}=0.029)$. VEGFA and PD-L1 overexpression were also associated with high $\mathrm{c}-$ 217 MET expression ( $\mathrm{p}=0.037$ and $\mathrm{p}=0.001$ respectively). CAIX expression was not associated with $\mathrm{c}-\mathrm{Met}$ 218 expression. PD-L1 overexpression remained significantly associated after logistic regression $(\mathrm{p}<0.001$, [2.3219 18.7]). The high expression of $c-M E T$ was not associated with VHL status $(p=0.239)$. No differences were 220 observed between progression-free and overall survival according to c-MET expression ( $\mathrm{p}=0.94$ and $\mathrm{p}=0.73$ 221 respectively, Figure 4).

\section{DISCUSSION}

224 Antiangiogenic VEGF-targeted therapies have been approved as first-line treatment in metastatic ccRCC. 225 However, despite showing efficacy and survival benefit, almost 20 to $30 \%$ of patients develop early disease 226 progression [5]. Thus, tumour recurrence in metastatic ccRCC has been one of the major challenges in patients 
treated with angiogenesis inhibitors, and explains the emergence of new strategies such as targeted immunotherapy and TKI targeting new pathways such as HGF/cMET [10].

It is important to acknowledge the limitations of our study. Firstly, this a retrospective study with patients included from 2 centers. The sample size is limited and partially explained by our rigorous inclusion criteria such as homogeneous histology (ccRCC) and sunitinib as first line treatment. Secondly, as recognized by the litterature, immunohistochemistry usually experienced poor standardization; however, in the case of c-Met antibody, this statement is limited as the same clone for c-MET antibody is widely used [20, 15, 9].

234 In the present study, we assessed c-MET status in a series of 90 patients with m-ccRCC treated by sunitinib as first line treatment with a median follow-up of 43 months. High c-MET expression was found in $69 \%$ of tumours. The FISH analysis revealed gains without $c$-MET amplification as previously found by MacherGoeppinger et al [22]. We observed a significant correlation between the percentage of gains by FISH and cMET expression by IHC, suggesting a potential mechanism for overexpression of the protein detected by IHC that could be inherited to metastatic tumour cells. Another explanation for c-MET overexpression may be related to post-translational modification, as previously described for tyrosine kinase receptors [23]. NGS analysis revealed no mutation on the c-MET gene, consistent with a previous study,, unlike papillary RCC, particularly type 1 , which shows nearly $20 \%$ c-MET mutations $[11,22]$.

As previously described, c-MET expression has been associated with poor prognostic factors such as nucleolar grade, sarcomatoid component and the presence of lymph nodes metastases [24]. A recent study by Peltola et al. assessed that c-MET high expression was also associated with poor survival in patients with metastatic RCC treated with sunitinib [25]. This difference may be explained by the non-homogeneous histology of the renal cell carcinoma included. Indeed, in their population $(n=137), n=107$ were clear cell renal cell carcinoma, whereas $\mathrm{n}=15$ were non ccRCC and for 15 tumors, the histology was missing. Non ccRCC have different carcinogenesis and there is no evidence whether first-line sunitinib is the optimal treatment in this subgroup [26, 27].

250 In our study, high c-MET expression was independently associated with PD-L1 by IHC. Shin et al first reported an association between c-MET and PD-L1 expressions in non-selected ccRCC [15]. In the present cohort, this association was observed in the primary ccRCC of patients with metastases. This cohort is more representative of patients likely to benefit from the corresponding inhibitors. Moreover, the independent association we identified, although limited by the sample size, gives argument for the combined use of c-MET inhibitors and targeted immunotherapy. Indeed, cabozantinib and nivolumab combination is currently investigated (NCT02496208) [28].

The HGF/cMET pathway has been described as an alternative antiangiogenic pathway that could be responsible for early resistance to anti-VEGF therapy [29]. In addition, chronic sunitinib treatment was demonstrated to lead to c-MET up regulation in vitro [30]. Consequently, we hypothesize that the response could be improved targeting c-MET pathway as well. Nevertheless, MET overexpression was not associated with progressive disease at first radiological evaluation, PFS and OS, in patients uniformly first-treated by sunitinib.

262 With VHL inactivation, HIF stabilization leads to the transcription of targeted genes, such as CAIX, VEGFA and c-MET whose expression and suggesting a correlation between $V H L$ status and HIF-targeted gene expression 264 [31, 32]. However, we did not observe a correlation between $V H L$ inactivation (VHL mutation or promoter 
265 methylation) and the expression of these targets genes suggesting the involvement of alternative pathways, such 266 as the MAP kinase and PI3K-AKT-mTOR pathways, in ccRCC oncogenesis, independent of VHL mechanisms $267[33,34]$.

268 In conclusion, the present study confirmed a high proportion of metastatic ccRCC showing a high c-Met protein 269 expression without association with sunitinib response. The independent association of c-MET expression with 270 PD-L1 expression, may suggest a potential benefit to the use of c-MET inhibitors with targeted immunotherapy 271 for these patients.

\section{COMPLIANCE WITH ETHICAL STANDARDS SECTION}

\section{Informed consent}

286 Informed consent was obtained from all individuals participants included in the study.

\section{Funding}

288 This work was supported by Novartis (PRIME research grant). The authors would like to acknowledge the Ligue 289 Contre le Cancer, the CORECT, CHU de Rennes and l'Institut National du Cancer (INCa) for their financial aid.

290 Conflict of interest

291 The authors have no conflict of interest to declare.

\section{ACKNOWLEDGMENTS}

296 The authors acknowledge the Centre de Ressources Biologiques (CRB) Santé BB-0033-00056 297 (http://www.crbsante-rennes.com) of Rennes for managing patient samples as well as Pascale Bellaud and 
298 Roselyne Viel for their technical support (Plateforme d'Histopathologie H2P2, Biosit, Université de Rennes1, 299 France).

300 
1. Ljungberg B, Campbell SC, Choi HY, Jacqmin D, Lee JE, Weikert S et al. The epidemiology of renal cell carcinoma. Eur Urol. 2011;60(4):615-21. doi:10.1016/j.eururo.2011.06.049.

304

305

2. Murai M, Oya M. Renal cell carcinoma: etiology, incidence and epidemiology. Curr Opin Urol. 2004;14(4):229-33.

3. Gupta K, Miller JD, Li JZ, Russell MW, Charbonneau C. Epidemiologic and socioeconomic burden of metastatic renal cell carcinoma (mRCC): a literature review. Cancer Treat Rev. 2008;34(3):193-205. doi:10.1016/j.ctrv.2007.12.001.

4. Gossage L, Eisen T, Maher ER. VHL, the story of a tumour suppressor gene. Nat Rev Cancer. 2015;15(1):55-64. doi:10.1038/nrc3844.

5. Abdullah SE, Perez-Soler R. Mechanisms of resistance to vascular endothelial growth factor blockade. Cancer. 2012;118(14):3455-67.

6. Harshman LC, Choueiri TK. Targeting the hepatocyte growth factor/c-Met signaling pathway in renal cell carcinoma. Cancer J. 2013;19(4):316-23. doi:10.1097/PPO.0b013e31829e3c9a.

7. Motzer RJ, Escudier B, McDermott DF, George S, Hammers HJ, Srinivas S et al. Nivolumab versus Everolimus in Advanced Renal-Cell Carcinoma. N Engl J Med. 2015;373(19):1803-13. doi:10.1056/NEJMoa1510665.

8. Choueiri TK, Escudier B, Powles T, Mainwaring PN, Rini BI, Donskov F et al. Cabozantinib versus Everolimus in Advanced Renal-Cell Carcinoma. N Engl J Med. 2015;373(19):1814-23. doi:10.1056/NEJMoa1510016.

9. Zhu C, Xu J, Li M, Zhao G, Cao H. Heterogeneity of c-Met expression in Chinese gastric cancer patients. Human pathology. 2015;46(12):1901-7. doi:10.1016/j.humpath.2015.06.025.

10. Stukalin I, Alimohamed N, Heng DY. Contemporary Treatment of Metastatic Renal Cell Carcinoma. Oncol Rev. 2016;10(1):295. doi:10.4081/oncol.2016.295.

11. Albiges L, Guegan J, Le Formal A, Verkarre V, Rioux-Leclercq N, Sibony M et al. MET is a potential target across all papillary renal cell carcinomas: result from a large molecular study of pRCC with CGH array and matching gene expression array. Clin Cancer Res. 2014;20(13):3411-21. doi:10.1158/10780432.CCR-13-2173.

12. Patard JJ, Rioux-Leclercq N, Masson D, Zerrouki S, Jouan F, Collet N et al. Absence of VHL gene alteration and high VEGF expression are associated with tumour aggressiveness and poor survival of renal-cell carcinoma. Br J Cancer. 2009;101(8):1417-24.

13. Patard JJ, Fergelot P, Karakiewicz PI, Klatte T, Trinh QD, Rioux-Leclercq N et al. Low CAIX expression and absence of VHL gene mutation are associated with tumor aggressiveness and poor survival of clear cell renal cell carcinoma. International journal of cancer Journal international du cancer. 2008;123(2):395-400.

14. Kammerer-Jacquet SF, Crouzet L, Brunot A, Dagher J, Pladys A, Edeline J et al. Independent association of PD-L1 expression with noninactivated VHL clear cell renal cell carcinoma-A finding with therapeutic potential. International journal of cancer Journal international du cancer. 2016. doi:10.1002/ijc.30429.

15. Shin SJ, Jeon YK, Kim PJ, Cho YM, Koh J, Chung DH et al. Clinicopathologic Analysis of PD-L1 and PD-L2 Expression in Renal Cell Carcinoma: Association with Oncogenic Proteins Status. Ann Surg Oncol. 2015. doi:10.1245/s10434-015-4903-7.

16. Rioux-Leclercq N, Karakiewicz PI, Trinh QD, Ficarra V, Cindolo L, de la Taille A et al. Prognostic ability of simplified nuclear grading of renal cell carcinoma. Cancer. 2007;109(5):868-74. 17. Bui MH, Seligson D, Han KR, Pantuck AJ, Dorey FJ, Huang Y et al. Carbonic anhydrase IX is an independent predictor of survival in advanced renal clear cell carcinoma: implications for prognosis and therapy. Clin Cancer Res. 2003;9(2):802-11. 

Expression in NSCLC Indicate a Favorable Prognosis in Defined Subgroups. PLoS One. 2015;10(8):e0136023. doi:10.1371/journal.pone.0136023. 19. Belaud-Rotureau MA, Parrens M, Carrere N, Turmo M, Ferrer J, de Mascarel A et al. Interphase fluorescence in situ hybridization is more sensitive than BIOMED-2 polymerase chain reaction protocol in detecting IGH-BCL2 rearrangement in both fixed and frozen lymph node with follicular lymphoma. Human pathology. 2007;38(2):365-72. doi:10.1016/j.humpath.2006.08.022. 20. Jurmeister P, Lenze D, Berg E, Mende S, Schaper F, Kellner U et al. Parallel screening for ALK, MET and ROS1 alterations in non-small cell lung cancer with implications for daily routine testing. Lung Cancer. 2015;87(2):122-9. doi:10.1016/j.lungcan.2014.11.018. 21. Jeuken JW, Cornelissen SJ, Vriezen M, Dekkers MM, Errami A, Sijben A et al. MS-MLPA: an attractive alternative laboratory assay for robust, reliable, and semiquantitative detection of MGMT promoter hypermethylation in gliomas. Lab Invest. 2007;87(10):1055-65. 22. Macher-Goeppinger S, Keith M, Endris V, Penzel R, Tagscherer KE, Pahernik S et al. MET predictive marker. Oncotarget. 2017;8(1):1046-57. doi:10.18632/oncotarget.13540.

23. Wethmar K, Schulz J, Muro EM, Talyan S, Andrade-Navarro MA, Leutz A. Comprehensive translational control of tyrosine kinase expression by upstream open reading frames. Oncogene. 2016;35(13):1736-42. doi:10.1038/onc.2015.233.

24. Gibney GT, Aziz SA, Camp RL, Conrad P, Schwartz BE, Chen CR et al. c-Met is a prognostic marker and potential therapeutic target in clear cell renal cell carcinoma. Annals of oncology : official journal of the European Society for Medical Oncology / ESMO. 2013;24(2):343-9. doi:10.1093/annonc/mds463.

25. Peltola KJ, Penttila P, Rautiola J, Joensuu H, Hanninen E, Ristimaki A et al. Correlation of c-Met Expression and Outcome in Patients With Renal Cell Carcinoma Treated With Sunitinib. Clinical genitourinary cancer. 2017. doi:10.1016/j.clgc.2017.01.021.

26. Banumathy G, Cairns P. Signaling pathways in renal cell carcinoma. Cancer Biol Ther. 2010;10(7):658-64.

27. Escudier B, Porta C, Schmidinger M, Algaba F, Patard JJ, Khoo V et al. Renal cell carcinoma: ESMO Clinical Practice Guidelines for diagnosis, treatment and follow-up. Annals of oncology : official journal of the European Society for Medical Oncology / ESMO. 2014;25 Suppl 3:iii49-56. doi:10.1093/annonc/mdu259.

28. Worley L. Cabozantinib and nivolumab for renal cell carcinoma. Lancet Oncol. 2015;16(15):e531. doi:10.1016/S1470-2045(15)00377-0.

29. Shojaei F, Lee JH, Simmons BH, Wong A, Esparza CO, Plumlee PA et al. HGF/c-Met acts as an alternative angiogenic pathway in sunitinib-resistant tumors. Cancer research. 2010;70(24):10090100. doi:10.1158/0008-5472.CAN-10-0489.

30. Zhou L, Liu XD, Sun M, Zhang X, German P, Bai S et al. Targeting MET and AXL overcomes resistance to sunitinib therapy in renal cell carcinoma. Oncogene. 2016;35(21):2687-97. doi:10.1038/onc.2015.343.

31. Keith B, Johnson RS, Simon MC. HIF1alpha and HIF2alpha: sibling rivalry in hypoxic tumour growth and progression. Nat Rev Cancer. 2012;12(1):9-22.

32. Pennacchietti S, Michieli P, Galluzzo M, Mazzone M, Giordano S, Comoglio PM. Hypoxia promotes invasive growth by transcriptional activation of the met protooncogene. Cancer Cell. 2003;3(4):34761.

33. Robb VA, Karbowniczek M, Klein-Szanto AJ, Henske EP. Activation of the mTOR signaling pathway in renal clear cell carcinoma. The Journal of urology. 2007;177(1):346-52. doi:10.1016/j.juro.2006.08.076.

34. Mendoza MC, Er EE, Blenis J. The Ras-ERK and PI3K-mTOR pathways: cross-talk and compensation. Trends Biochem Sci. 2011;36(6):320-8. 


\section{FIGURE LEGENDS}
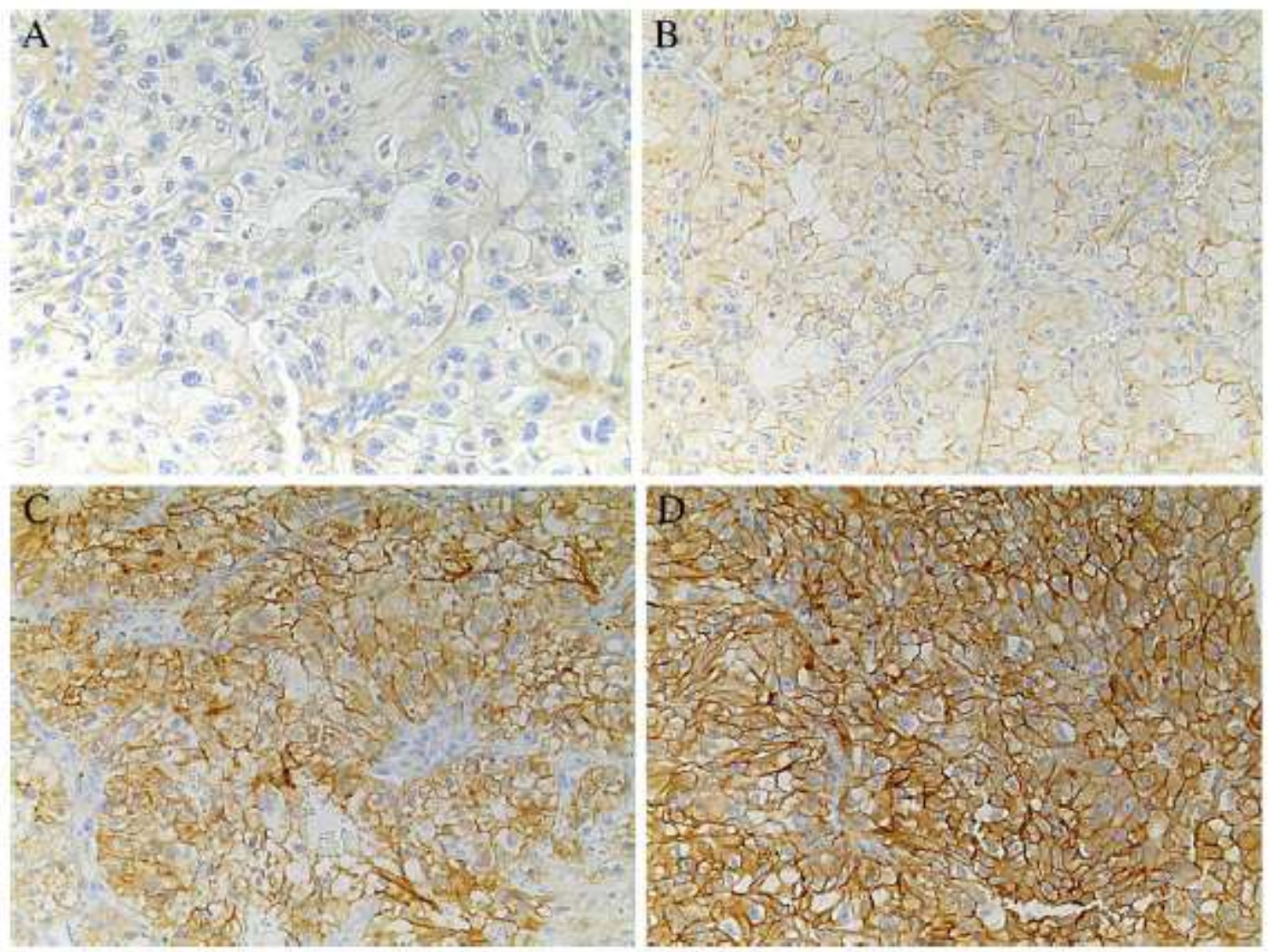

401

402 Figure 1: Intensity of c-MET expression:

403 A) Absence of c-MET expression, IHC x100

404 B) Low expression of c-MET in tumor cells, IHC x100

405 C) Moderate expression of c-MET in tumor cells, IHC x100

406 D) High expression of c-MET in tumor cells, IHC x100

407

408 

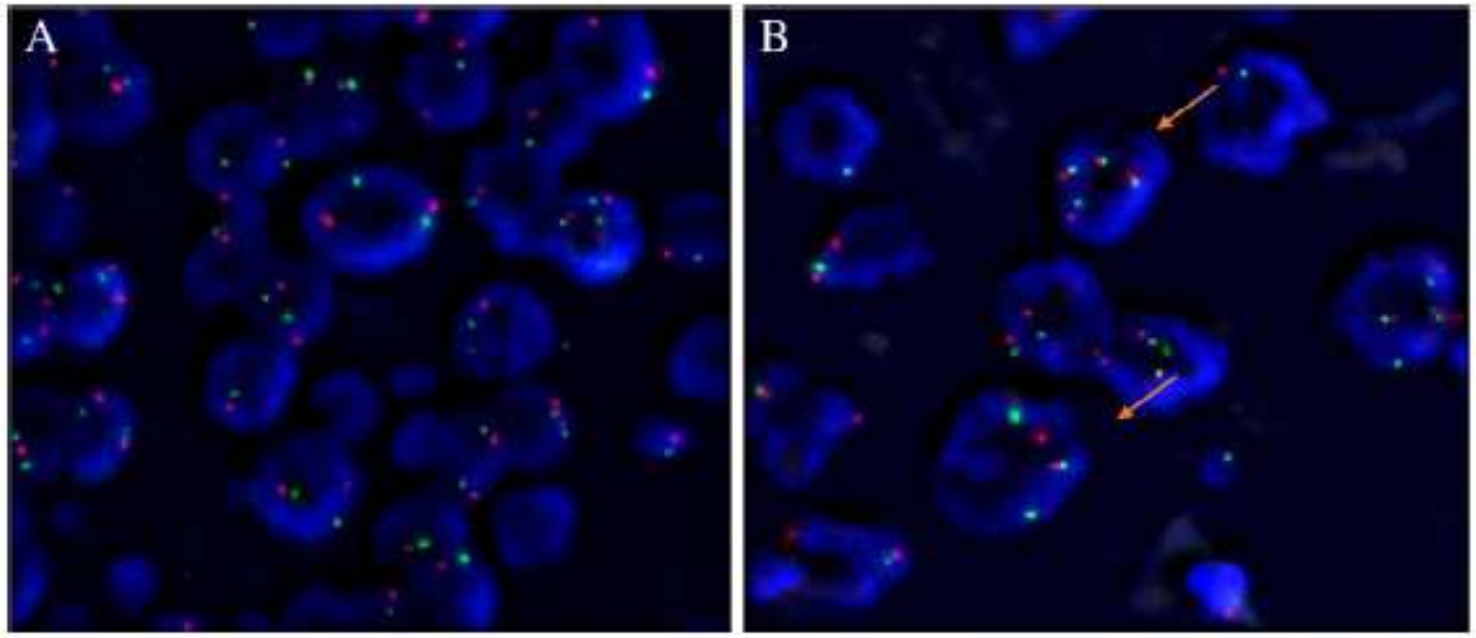

409

410 Figure 2: FISH analysis

411 A) Nuclei with a normal hybridization pattern (2 green and 2 orange signals)

412 B) Nuclei with a c-MET gain exhibit more than 2 green signals (arrows).

413

414

415

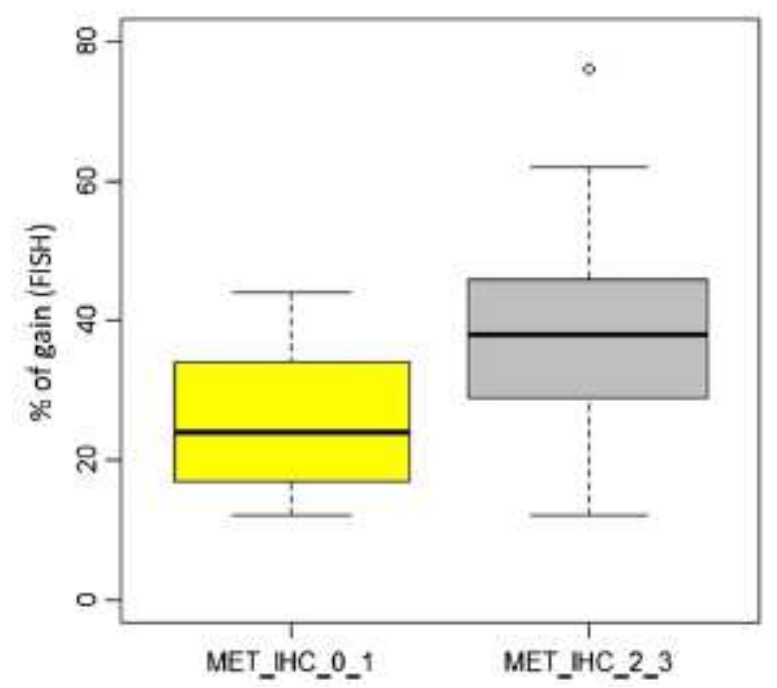

416 Figure 3: Percentage of gains (FISH) according to c-MET expression (IHC).

417 
A

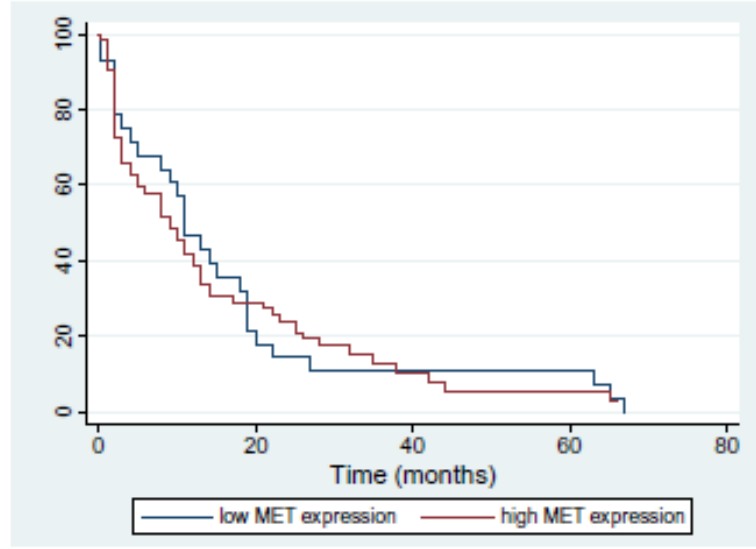

B

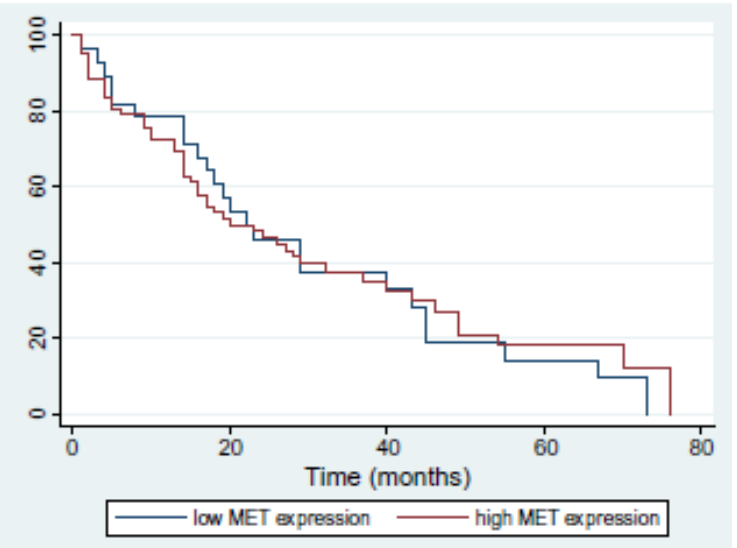

420 Figure 4: Progression-free survival (PFS) and overall survival (OS) after sunitinib according to c-MET

421 expression in metastatic ccRCC:

422 A) PFS: median survival: low: 11 months, high: 9 months $(\mathrm{p}=0.828)$

423 B) OS: median survival: low: 22 months, high: 20 months ( $\mathrm{p}=0.860$ )

424

425

426

427

428

429

430

431

432

433

434

435

436

437

438

439

440

441

442

443

444

445

446

447

448 


\begin{tabular}{|c|c|c|}
\hline Characteristics & No & $\%$ \\
\hline \multicolumn{3}{|l|}{ Age (years) } \\
\hline Mean & 61.3 & \\
\hline Range & $37-85$ & \\
\hline \multicolumn{3}{|l|}{ Sex } \\
\hline Male & 34 & $37.8 \%$ \\
\hline Female & 56 & $62.2 \%$ \\
\hline \multicolumn{3}{|l|}{ Heng score } \\
\hline Favorable & 20 & $22.2 \%$ \\
\hline Intermediate & 43 & $47.8 \%$ \\
\hline Poor & 27 & $30.0 \%$ \\
\hline \multicolumn{3}{|l|}{ T stage } \\
\hline $\mathrm{T} 1$ & 14 & $15.6 \%$ \\
\hline $\mathrm{T} 2$ & 8 & $8.9 \%$ \\
\hline T3 & 63 & $70.0 \%$ \\
\hline $\mathrm{T} 4$ & 5 & $5.6 \%$ \\
\hline \multicolumn{3}{|l|}{$\mathrm{N}$ stage } \\
\hline No & 75 & $83,3 \%$ \\
\hline $\mathrm{N} 1-\mathrm{N} 2$ & 15 & $16,7 \%$ \\
\hline \multicolumn{3}{|l|}{ M stage } \\
\hline Mo & 40 & $44.4 \%$ \\
\hline M1 & 50 & $55.6 \%$ \\
\hline \multicolumn{3}{|l|}{ Tumor size $(\mathrm{cm})$} \\
\hline Mean & 9.6 & \\
\hline Range & $2-20$ & \\
\hline \multicolumn{3}{|l|}{ ISUP nucleolar grade } \\
\hline Grade 2 & 7 & $7.8 \%$ \\
\hline Grade 3 & 33 & $36.7 \%$ \\
\hline Grade 4 & 50 & $55.6 \%$ \\
\hline \multicolumn{3}{|l|}{ RECIST 1} \\
\hline Complete response & 1 & $1.1 \%$ \\
\hline Partial response & 27 & $30.0 \%$ \\
\hline Stable disease & 34 & $37.8 \%$ \\
\hline Progressive disease & 28 & $31.1 \%$ \\
\hline
\end{tabular}

452 Table 1. Summary of the clinical and histopathological characteristics of 90 patients with metastatic 453 ccRCC treated by first line sunitinib. 


\begin{tabular}{|c|c|c|c|c|c|}
\hline Variables & $\begin{array}{l}\text { MET low } \\
(n=28)\end{array}$ & $\%$ & $\begin{array}{l}\text { MET high } \\
(n=62)\end{array}$ & $\%$ & $p$-value \\
\hline \multicolumn{6}{|l|}{ Clinical and radiological data } \\
\hline Age $>65$ years & 14 & $50,0 \%$ & 23 & $37.1 \%$ & $0.249 \dagger$ \\
\hline Good/intemediate prognosis (Heng score) & 21 & $75.0 \%$ & 42 & $67.7 \%$ & $0.487 \dagger$ \\
\hline Distant lymph node metastasis & 11 & $39.3 \%$ & 28 & $45.2 \%$ & $0.603 \dagger$ \\
\hline Pulmonary metastasis & 22 & $78.6 \%$ & 46 & $74.2 \%$ & $0.655 \div$ \\
\hline Bone metastasis & 17 & $60.7 \%$ & 31 & $50.0 \%$ & $0.346 \dagger$ \\
\hline Liver metastasis & 8 & $28.6 \%$ & 13 & $21.0 \%$ & $0.430 \dagger$ \\
\hline Cerebral metastasis & 7 & $25.0 \%$ & 12 & $19.4 \%$ & $0.544 \dagger$ \\
\hline Multiple metastasis & 22 & $78.6 \%$ & 47 & $75.8 \%$ & $0.774 t$ \\
\hline Progressive disease (RECIST) & 7 & $25.0 \%$ & 21 & $33.9 \%$ & $0.400 \dagger$ \\
\hline \multicolumn{6}{|l|}{ Pathological analysis } \\
\hline Size $>7 \mathrm{~cm}$ & 19 & $67.9 \%$ & 39 & $62.9 \%$ & $0.649 \dagger$ \\
\hline Nucleolar ISUP grade 4 & 11 & $39.3 \%$ & 39 & $62.9 \%$ & $0.037+$ \\
\hline Sarcomatoid component & 2 & $7.1 \%$ & 17 & $27.4 \%$ & $0.029 \div$ \\
\hline Tumor necrosis & 20 & $71.4 \%$ & 51 & $82.3 \%$ & $0.244 \div$ \\
\hline Microvascular invasion & 13 & $46.4 \%$ & 28 & $45.2 \%$ & $0.911 \dagger$ \\
\hline T3-T4 stage & 22 & $78,6 \%$ & 46 & $74.2 \%$ & $0.655 \dagger$ \\
\hline Hilar fat infiltration & 11 & $39.3 \%$ & 31 & $50.0 \%$ & $0.346 \dagger$ \\
\hline Peri-renal fat infiltration & 16 & $57.1 \%$ & 29 & $46,8 \%$ & $0.362 \dagger$ \\
\hline Venal invasion & 12 & $42.9 \%$ & 29 & $46.8 \%$ & $0.730 \dagger$ \\
\hline N1-N2 stage & 0 & $0.0 \%$ & 15 & $24.2 \%$ & $0.004^{4}$ \\
\hline Ml stage & 13 & $46.4 \%$ & 37 & $59.7 \%$ & $0.242 \uparrow$ \\
\hline \multicolumn{6}{|l|}{ Immunohistochemistry } \\
\hline CAIX $>85 \%$ & 7 & $25.0 \%$ & 21 & $33.9 \%$ & $0.400 \dagger$ \\
\hline VEGFA $>30 \%$ & 11 & $39.3 \%$ & 39 & $62.9 \%$ & $0.037 \dagger$ \\
\hline PD-L1 (2-3 intensity) * & 13 & $46.4 \%$ & 53 & $85.5 \%$ & $0,001 \div$ \\
\hline PD-1 (2-3 density) & 11 & $39.3 \%$ & 37 & $59.7 \%$ & $0.073 \dagger$ \\
\hline \multicolumn{6}{|l|}{ VHL status } \\
\hline VHL mutation & 23 & $82.1 \%$ & 41 & $66.1 \%$ & $0.121 \dagger$ \\
\hline Promoter methylation & 2 & $7.1 \%$ & 8 & $12.9 \%$ & $0.718 \ddagger$ \\
\hline VHL inactivation & 25 & $89.3 \%$ & 49 & $79.0 \%$ & $0.239 \div$ \\
\hline
\end{tabular}

4, $\chi^{2}$ test; $\ddagger$, Fisher exact test

RECIST 1: First RECIST evaluation, CR, complete response, PR, partial response; SD, stable disease; PD, progressive disease

*Independent variable after logistic regression

455 Table 2. Summary of histopathological and immunohistochemical characteristics and VHL status of 456 tumors according to c-MET expression. 